Supplement of Hydrol. Earth Syst. Sci. Discuss., 12, 13123-13147, 2015

http://www.hydrol-earth-syst-sci-discuss.net/12/13123/2015/

doi:10.5194/hessd-12-13123-2015-supplement

(C) Author(s) 2015. CC Attribution 3.0 License.

(c) (i)

\title{
The yearly amount and characteristics of deep-buried phreatic evaporation in hyper-arid areas
}

\section{H. Li et al.}

Correspondence to: $\mathrm{H} . \mathrm{Li}$ (dhlhs69@163.com)

The copyright of individual parts of the supplement might differ from the CC-BY 3.0 licence. 
3 The Dunhuang Mogao Grottoes are representative examples of cave-style

4 Buddhist temples. These ancient caves remain well-preserved to the present day, and

5 have become an important part of Buddhist heritage (Fig. 1).

6

7

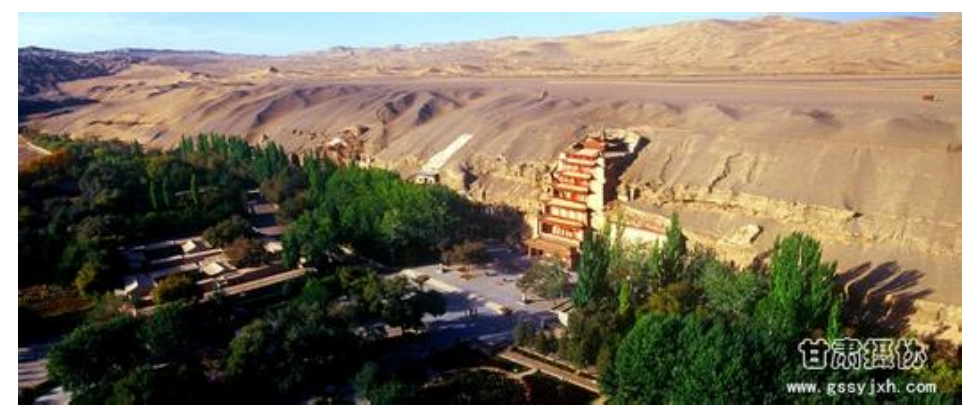

Fig. 1. The Mogao Grottoes of Dunhuang.

8 Due to their long history, grand scale, rich content, and state of preservation, the

9 Dunhuang Mogao Grottoes were listed in 1987 in their Directory of World Cultural

10 Heritage by the United Nations Educational, Scientific, and Cultural Organization

11 (UNESCO). However, a survey found that after ca. 1600 years since their creation,

12 about $50 \%$ of the wall paintings have suffered deteriorating diseases (Fig. 2).

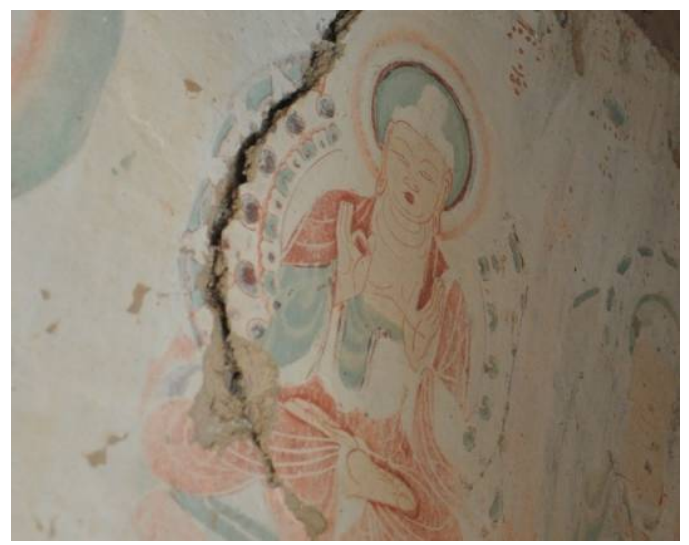

(a) Delaminating (Cave 387).

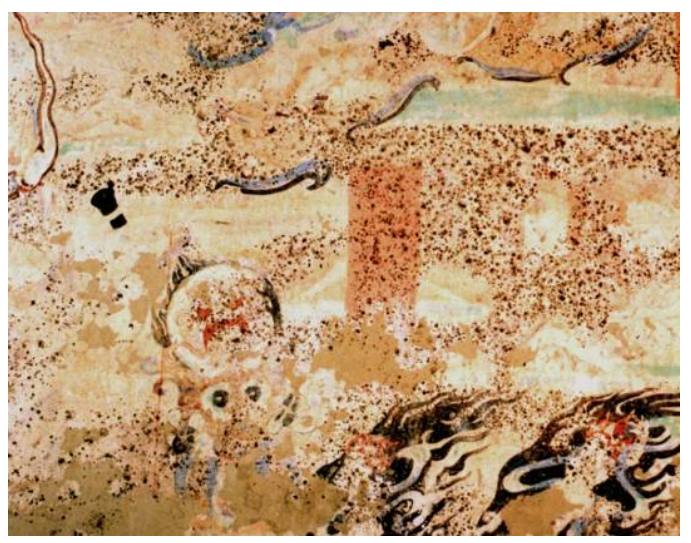

(b) Mildew pollution (Cave 53). 


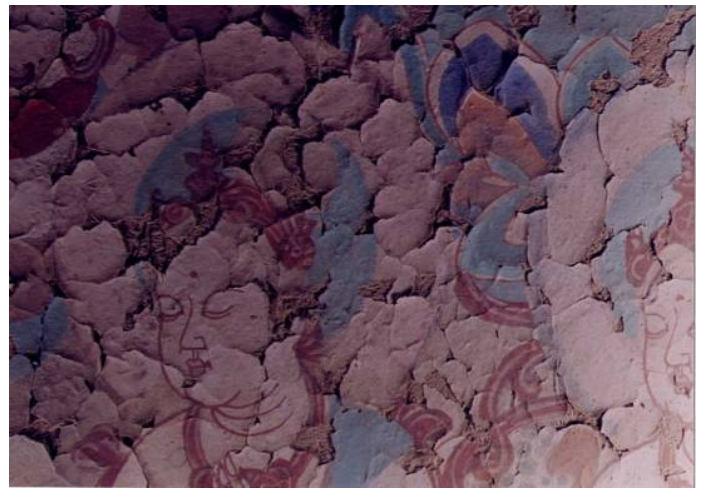

(c) Chapping and flaking (Cave 126).

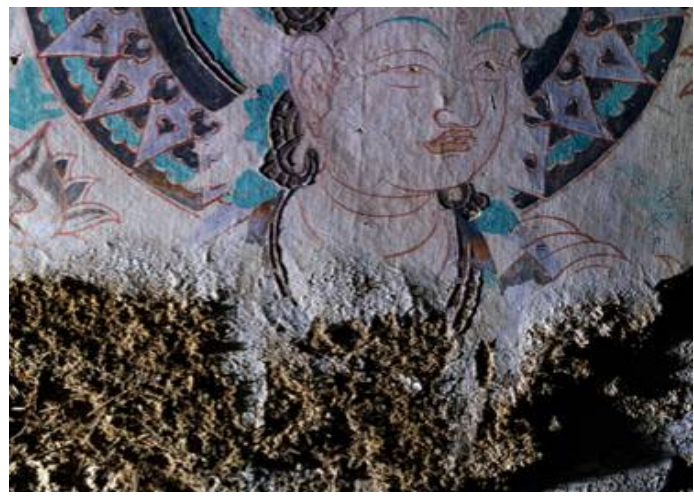

(d) Efflorescence (Cave 55).

Fig. 2. Representative diseases on the mural paintings in the Mogao Grottoes.

Due to a lack of vegetation protection, aeolian desertification, gravel desertification, and frequent sandstorms are typical characteristics of Mogao surrounding. It is not advantageous to Mogao Grottoes protection. Thus, Prheatic

18 water has very important scientific value with respect to recovering vegetation on

19 desertified land and for re-evaluation of Phreatic water resources in hyper-arid areas.

20 This study also facilitates preservation of the cultural relics.

21 In 2010-2015, we did this experiment in the greenhouse-air condition system, and 22 same time used another greenhouse-air condition system to go on monitoring the 23 basic phreatic evaporation (Fig.3-5).

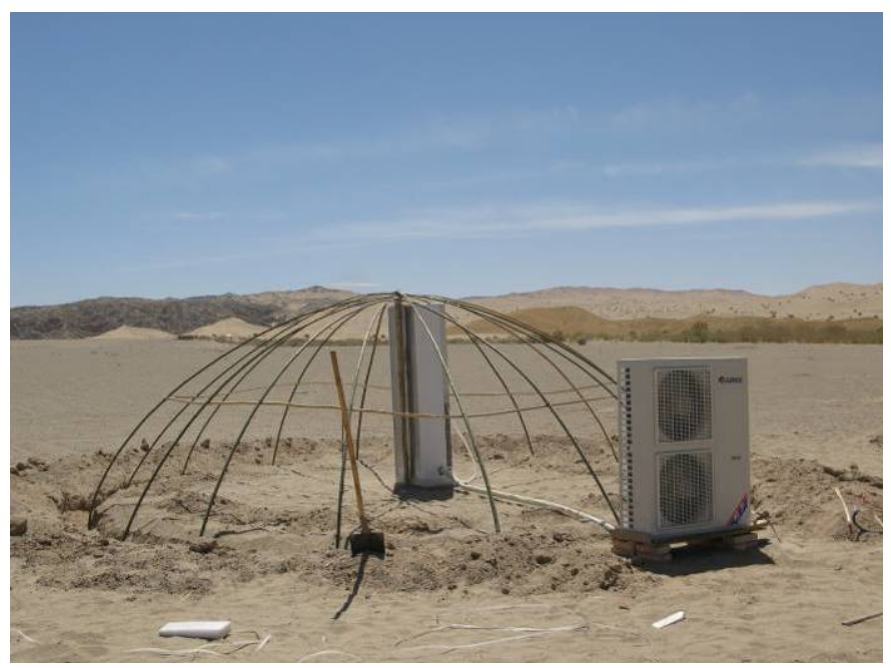




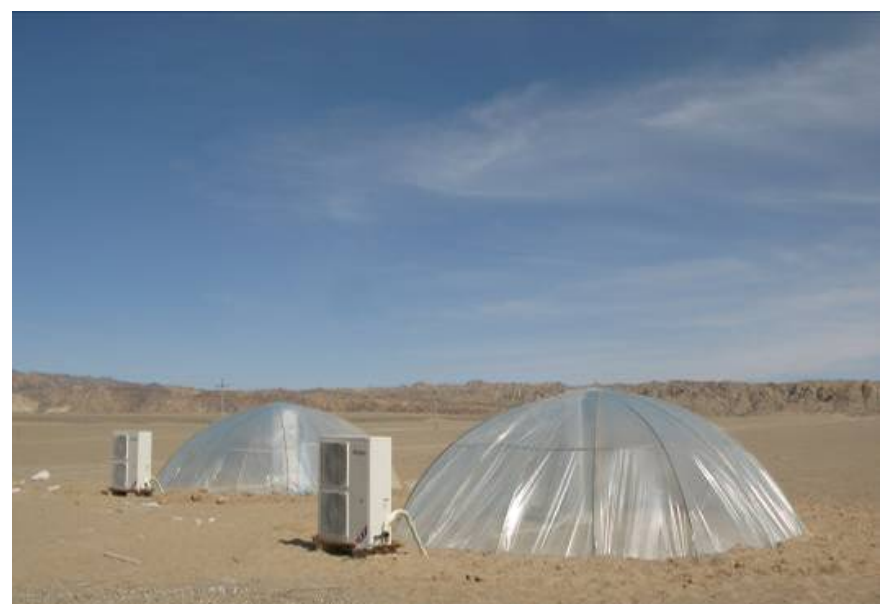

Fig. 4. The experiment of takes back 10mm rainfall and control-shed (2011-2015)

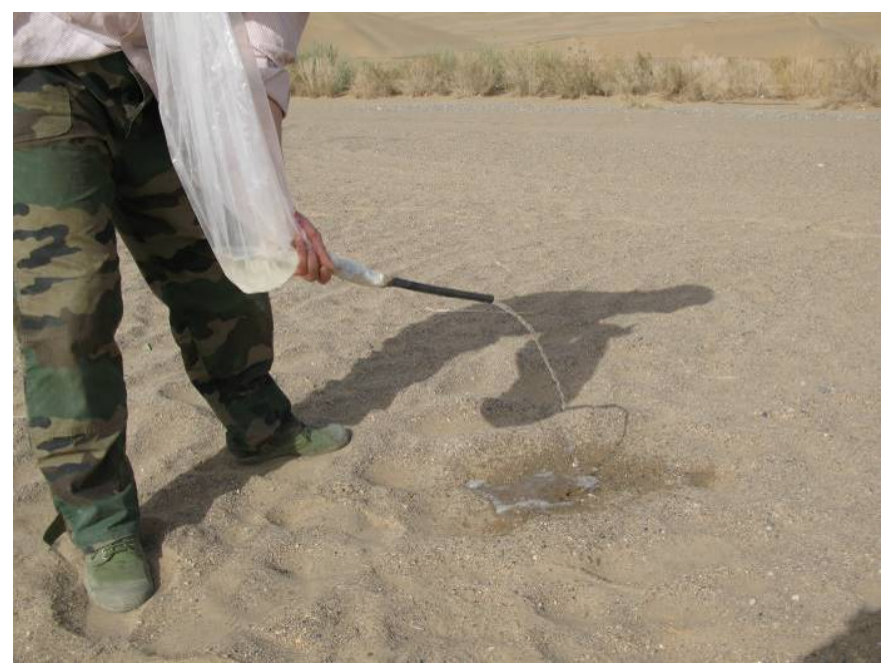

Fig. 5. Discharges collected evaporation water

30 In this paper, we measured and analyzed the yearly evaporation quality 31 characteristics of deep-buried phreatic water in extremely arid area at the top of

32 Mogao Grottoes in Dunhuang City, located in northwest China's Gansu province, by

33 using a closed greenhouse-air conditioner method from 2010 to 2015, and analyzed

34 the new running mechanism through humidity and temperature of 50 to $500 \mathrm{~cm}$ soil

35 layer, which represented the heterothermozone.

36 After 6 years monitoring of PE, we determined the annual evaporation is $4.52 \mathrm{~mm}$

37 in hyper-arid area. The PE has sinusoidal characteristics and changes along with soil

38 yearly temperature variation. Accordingly, analysis of the monitoring temperature and 
39 humidity in 50-500 $\mathrm{cm}$ soil shows that there exist conditions and migration 40 mechanisms for PW in the heterothermozone and deeper soil.

41 We found that there exists phreatic evaporation, i.e., the groundwater-soil-plant42 atmospheric continuum (GSPAC) water transports upward. This work break through 43 the traditional conception of deep-buried phreatic evaporation does not exist. We 44 found that the evaporation of phreatic water $(4.52 \mathrm{~mm})$ in this area is relatively larger 45 for survival of drought-tolerant vegetation; it has very important scientific value with 46 respect to recovering vegetation on desertified land and for re-evaluation of PW 47 resources in hyper-arid areas.

50 We hope these pictures be useful.

51 Best wishes!

53 Sincerely

54 Li Hongshou 